\title{
Physico-Chemical and Microbiological Quality Assessment of Ice Blocks Sold in Selected Wet Markets in Manila, Philippines
}

\author{
Leandro F. Salazar, ${ }^{1}$ Trishia Alexis I. Alvez, ${ }^{1}$ Janine Marie B. Balbedina, ${ }^{1}$ \\ ${ }^{1}$ College of Public Health, University of the Philippines Manila \\ ${ }^{2}$ Department of Environmental and Occupational Health, College of Public Health
}

Javier Alfonso A. Torres, ${ }^{1}$ Ivanah Y. Tupaz, ${ }^{1}$ Marian Fe Theresa C. Lomboy ${ }^{2}$ and Romeo R. Quizon ${ }^{2}$

\begin{abstract}
Objective. The study aimed to determine the physico-chemical and microbiological quality of ice blocks sold in selected wet markets located in the city of Manila.

Methods. Twenty-eight samples were collected from three markets. Microbiological quality was analyzed in terms of the presence or absence of coliforms with $\mathrm{E}$. coli as indicator organism. Physico-chemical quality was determined by measuring turbidity, apparent color, $\mathrm{pH}$, iron, and residual chlorine. Measurements obtained were compared with the 2007 Philippine National Standards for Drinking Water (PNSDW).
\end{abstract}

Results. Results showed that all samples tested positive for coliforms while 25 out of the 28 samples were positive for E. coli. Mean turbidity was $2.74 \pm 3.68$ NTU; for both apparent color and iron tests, all samples complied with the PNSDW standard limit set; mean $\mathrm{pH}$ was $6.15 \pm 0.64$; and mean residual chlorine was $0.06 \pm 0.02 \mathrm{mg} / \mathrm{L}$. Average values of apparent color and iron comply with the PNSDW standards. Six out of 28 samples had turbidity values exceeding the standards. All samples were found to have residual chlorine levels below the standards.

Conclusion. Ice in markets do not comply with key 2007 PNSDW standards and findings warrant strict compliance of ice quality from manufacturers to the point of distribution to protect consumer health.

Key Words: physico-chemical analysis, microbiological analysis, Escherichia coli

\section{INTRODUCTION}

Ice is a common and popular commodity in the Philippines with a wide range of uses. Wet markets are major sources of ice in the country wherein the product is usually distributed and sold in the form of ice blocks. These ice blocks are distributed alongside other fresh produce and are also used for the preservation of fresh products such as seafood and raw meats. Street food vendors utilize ice blocks to cool their products especially drinks.

Ice is water. Strict regulation of water quality exists, but that same level of monitoring is not translated when it comes to consumable ice quality. Poor water quality and/or improper handling and transport practices may lead to ice becoming a vector of pathogens causing outbreaks of gastroenteritis. ${ }^{1}$

There are only few government issued decrees that deal

Corresponding Author: Romeo R.Quizon, MSc, Eng'g Department of Environmental and Occupational Health College of Public Health

University of the Philippines Manila

625 Pedro Gil Street, Ermita Manila 1000 Philippines

Telephone: +6325247102

Email: rrquizon@up.edu.ph with ice and its quality as a consumable item. The Code on Sanitation of the Philippines Section 32 Chapter 5 Section 5.d states that ice plants must only use potable water in the manufacture of ice. Moreover, precautionary measures shall 
be taken to protect ice from source contamination during transport and storage. ${ }^{2}$ These measures specified in Section 5.d is divided into five categories to ensure that the quality of ice from ice plants are at par with the standards. The rules and regulations are written as follows: (1) securing a sanitary permit prior to the plant's operation,(2) requiring a valid health certificate issued by the local health office from all workers directly involved in the preparation, manufacturing, handling and transporting of ice; (3) strict compliance of ice plants to the standards of sanitation prescribed by the Department of Health involving the building or structures, equipment, water supply, health of employees, plumbing and quality of air used for agitation; (4) All facilities must be kept clean, in good condition and free of rust or other foreign materials; (5) operation of ice plants is the responsibility of the owner, operator or whoever is in-charge and must be accomplished in a sanitary manner and lastly (6) precautionary measures shall be taken during transportation and delivery of ice to protect it from any contamination. ${ }^{[2]}$ The level of a water constituent or numerical value of a parameter, which does not result in significant health risk, is provided in the Philippine National Standards for Drinking Water (PNSDW). The 2007 PNSDW is one of the water quality standards used. The Administrative Order regulates the quality of water used in the manufacture of ice. ${ }^{3}$ It does not, however, cover the quality of ice being sold by market vendors. In general, ice block quality in the Philippines is unregulated. While the 2007 PNSDW ensures the quality of water used in the manufacture of ice, it does not regulate the ice quality at the point of distribution. No prior study has been conducted in the Philippines with regard to the regulation of ice quality. The lack of literature and regulation specifically directed to ice quality is very alarming. Its quality and compliance with the standards set is vital because ice is water.

The study covers key physico-chemical parameters. The parameters that were tested are turbidity, apparent color, iron, residual chlorine, $\mathrm{pH}$, and temperature. The primary reason for physico-chemical parameters chosen is to assess the general stability of water quality. Turbidity testing is significant for the assessment of effective disinfection of water. Increased turbidity levels can affect the process of water chlorination by forming chloroform, thus, assessing the turbidity levels of ice is an early indicator of the disinfection level of water. In relation with turbidity, color can reflect the presence of humic substances which are the organic constituents of soil, peat and coal. Increased levels of iron may cause deposition of iron bacteria which greatly decreases the potability of water. The changes in $\mathrm{pH}$, on the other hand, affect the efficiency of chlorine disinfection which works to remove microorganisms in water. Testing for the $\mathrm{pH}$ level ice helps identifying the probability of microorganisms being present in the ice. Temperature can also affect the activity of microorganisms in water. Measuring the temperature may provide an overview of the possible microorganisms and their state of activity. Lastly, testing for the residual chlorine indicates that sufficient amount of chlorine is still present by the time of the analysis and recontamination of ice has not occurred during delivery, storage and handling. Although there are 14 mandatory parameters stated in the 2007 PNSDW that indicate general stability of water, the research focused only on the abovestated parameters due to resource constraints.

The study aims to determine the physico-chemical and microbiological quality of ice blocks sold in registered wet markets located in the city of Manila. Specifically, the study aims: (1) to determine the physico-chemical quality of ice blocks sold in selected wet markets located in the city of Manila in terms of turbidity, apparent color, $\mathrm{pH}$ and temperature, iron and residual chlorine, and (2) to determine the microbiological quality of ice blocks collected from the selected wet markets located in the city of Manila by testing for Escherichia coli.

\section{Delimitations of the Study}

The study was delimited to the assessment of the physico-chemical and microbiological quality of ice blocks sold in three selected wet markets in the city of Manila. The investigators analyzed only the ice sold to them on the designated day of collection. Analyzing only the ice samples given may not fully ensure the representativeness of the ice block, but it may provide an estimate of the quality of ice that a customer usually procures. In order to minimize this limitation, four ice block samples were bought from each vendor at different times and different days (during a weekday and a weekend). There was no available information regarding the quality of water used in the production of ice since the researchers did no further tracing of the big scale source of ice. Testing for the water quality of pre-manufactured ice was also not performed. In general, the study focused only on the quality of ice blocks sold to customers directly from the wet markets. It did not cover delivery, handling and storage of ice blocks as wells as the pre-manufactured water quality.

Due to resource constraints, the research focused only on key physico-chemical parameters instead of the complete 14 parameters as provided by the 2007 PNSDW under the assumption that compliance of ice samples to the PNSDW must be within standard values of any chosen parameter. Therefore, non-compliance to the PNSDW can be sufficiently indicated by any value of one or more of the chosen parameters not falling within the standards set by the PNSDW. The study utilized the 2007 PNSDW due to the unavailability of the 2017 PNSDW during the time the study was implemented.

\section{METHODS}

\section{Sample Collection}

The study was conducted in the city of Manila. Ice block samples were collected from three markets that were included in the study. Market A has 2 ice vendors ( 8 samples), Market B has 3 (12 samples), while Market C has 2 (8 samples). The samples that were collected have an estimated dimension of 14 " x 10 " x 7 " and a volume of approximately one (1) liter that 
was bought at a market price of $\mathrm{PhP} 10.00$. The location in the main ice block from where the samples were extracted was not specified as the researchers considered how ice is actually sold wherein vendors randomly give buyers a block of ice. Four samples were collected per ice vendor present in the market and were aseptically placed in separate sterile airtight glass jars in two separate days, one during a weekday and one during a weekend, at two different time points per day to achieve representativeness. A total of 28 ice block samples were collected and analyzed for the presence of $E$. coli as well as the physico-chemical parameters: turbidity, $\mathrm{pH}$ and temperature, apparent color, iron and residual chlorine. The ice block samples were divided into smaller pieces by the vendor and placed in the plastic bags provided by the vendors. A sterile dextrose glass jar with $300 \mathrm{~mL}$ capacity was used to contain approximately $250 \mathrm{~mL}$ of the ice block sample for microbiological analysis, while the remaining volume (750 $\mathrm{mL}$ ) of the ice block sample for physico-chemical analysis was placed in an airtight glass jar with a volume capacity of $1000 \mathrm{~mL}$. Residual chlorine, apparent color, and $\mathrm{pH}$ and temperature were immediately tested after the ice has melted. Analysis of the other parameters was done when the ice sample has completely melted and has reached room temperature. The samples were analyzed for physico-chemical parameters within six hours from sample collection. Standard methods were used in the analysis of the different parameters in accordance with the $22^{\text {nd }}$ edition of the Standard Methods for the Examination of Water and Wastewater (SMEWW). Analysis was done in triplicates for the physico-chemical parameters and only once for $E$. coli testing. The mean and standard deviation were calculated for all parameters. The median, minimum and maximum values were also shown to describe the results of analysis for the physico-chemical parameters. On the other hand, the results of the E. coli test were described in terms of frequency counts and percentages.

\section{Physico-chemical Methods}

A turbidimeter employing the nephelometric method was used to measure the turbidity of the samples. The apparent color of the samples under investigation was measured semi-quantitatively by visual comparison of the measurement solution with the color fields of the color card and comparator block with long test tubes 5 - 10 - 20 - 30 $40-50-70-100-150$ of the Hazen McColortest ${ }^{\mathrm{TM}}$ (Merck Millipore, Germany). Residual chlorine was determined semiquantitatively by applying the Diethyl-p-phenylenediamine (DPD) method through visual comparison of the color of the measurement solution with the color fields of a color card and sliding comparator $0.10-0.20-0.30-0.60-1.0$ - $1.5 \mathrm{mg} / \mathrm{L} \mathrm{Cl}_{2} \mathrm{McColortest}^{\mathrm{TM}}$. The $\mathrm{pH}$ and temperature were tested using a properly calibrated $\mathrm{pH}$ meter. For the determination of total iron, the phenanthroline method was used and acid-washed glassware was used for the analysis. Two milliliters of concentrated hydrochloric acid $(\mathrm{HCl})$ and $1 \mathrm{~mL}$ of hydroxylamine hydrochloride $\left(\mathrm{NH}_{2} \mathrm{OH} . \mathrm{HCl}\right)$ solution were added to $50 \mathrm{~mL}$ of the sample and the reagent blank. The sample and blank were heated to boiling until the volume was reduced to 15 to $20 \mathrm{~mL}$ to ensure dissolution of all the iron present. After the sample and blank have cooled to room temperature, ten milliliters of ammonium acetate $\left(\mathrm{NH}_{4} \mathrm{C}_{2} \mathrm{H}_{3} \mathrm{O}_{2}\right)$ buffer solution and $4 \mathrm{~mL}$ phenanthroline solution were added, and the sample and blank were diluted with distilled water. After 15 minutes, the sample was read against the reagent blank for absorbance at a wavelength of $510 \mathrm{~nm}$ in the spectrophotometer. Iron concentration in ppm was calculated using the equation: absorbance $=0.1382 \mathrm{x}-0.0055267$, where $\mathrm{x}$ is the concentration of iron. Reference solutions were used in analysis of samples requiring visual comparison and the use of equipment, such as the determination of turbidity, apparent color, $\mathrm{pH}$ and temperature, and residual chlorine.

\section{Microbiological Examination}

The microbiological analysis was done using the Readycult ${ }^{\circledR}$ Coliforms 100 (Merck Millipore, Germany) showing the presence or absence of bacteria. A preweighed enzyme medium, packed in individual containers, was aseptically added to $100 \mathrm{~mL}$ of the sample in a sterile, transparent non-fluorescent glass container. The container was aseptically capped and mixed thoroughly to ensure dissolution of the enzyme medium. The sample was incubated for $24 \pm 1$ hour at $35-36 \pm 1^{\circ} \mathrm{C}$. The vessel was visually checked for a blue-green color. If the sample were blue-green, it means that coliform bacteria are present in the sample and should be examined for fluorescence. Using $366 \mathrm{~nm}$ as the wavelength, the vessel was checked for the presence of a uniform, bright, light-blue glow. The presence of fluorescence indicates the presence of $E$. coli. For secondary confirmation, approximately $5 \mathrm{~mL}$ of broth was poured into a test tube and 5 drops of Kovac's indole reagent were added to confirm the presence of $E$. coli through the appearance of a red ring. Absence of blue-green color denotes negative for coliform bacteria. A negative control (100 $\mathrm{mL}$ distilled water) and a positive control (accomplished by inoculating E. coli to $100 \mathrm{~mL}$ of distilled water) were prepared for quality control of the media.

\section{RESULTS}

The summary of results of the analysis of physicochemical parameters for all markets is shown in Table 1.

Microbiological quality analysis results per market during weekdays and weekends are shown in Table 2.

Out of the 28 samples, 25 samples or $89.29 \%$ were confirmed to be positive for $E$. coli. Ice samples from Market A were $100 \%$ positive for $E$. coli, samples from Market B were 83.33\% positive, and samples from Market $C$ were $87.5 \%$ positive. The percentage of $E$. coli positive results for weekdays were $92.86 \%$ while on weekends, it was $85.71 \%$. All samples were positive for coliforms. 
Table 1. Age, sex, length of stay, hospitalization costs per type of case among selected hospitals, January-December 2013, Total Cases $=1,415$

\begin{tabular}{|c|c|c|c|c|c|}
\hline & Turbidity (NTU) & Apparent Color (apparent color units) & $\mathrm{pH}$ & Iron (mg/L) & Residual chlorine (mg/L) \\
\hline PNSDW Standard & 5 & 10 & 6.5 to 8.5 & 1 & 0.3 to 1.5 \\
\hline Mean +/- SD & $2.74 \pm 3.68$ & $2.33 \pm 2.41$ & $6.15 \pm 0.64$ & $0.20 \pm 0.20$ & $0.06 \pm 0.02$ \\
\hline Median & 1.13 & 1.70 & 6.61 & 0.13 & 0.05 \\
\hline Minimum & 0.10 & 0 & 5.17 & 0.06 & 0.05 \\
\hline Maximum & 10.3 & 5 & 7.53 & 0.92 & 0.10 \\
\hline
\end{tabular}

Table 2. Microbiological results of unwashed ice samples

\begin{tabular}{cccc}
\multirow{2}{*}{ Markets } & $\begin{array}{c}\text { Day of sample } \\
\text { collection }\end{array}$ & \multicolumn{2}{c}{$\begin{array}{c}\text { Ice block samples } \\
\text { that contain } \text { E. coli }\end{array}$} \\
\cline { 3 - 4 } & Weekday $\mathrm{n}=4$ & 4 & $100 \%$ \\
\multirow{2}{*}{ Market $\mathrm{A}$} & Frequency & Percentage \\
& Weekend $\mathrm{n}=4$ & 4 & $100 \%$ \\
\hline \multirow{2}{*}{ Market $\mathrm{B}$} & Weekday $\mathrm{n}=6$ & 5 & $83.33 \%$ \\
& Weekend $\mathrm{n}=6$ & 5 & $83.33 \%$ \\
\hline \multirow{2}{*}{ Market C } & Weekday $\mathrm{n}=4$ & 4 & $100 \%$ \\
& Weekend $\mathrm{n}=4$ & 3 & $75 \%$ \\
\hline \multirow{2}{*}{ All 3 Markets } & Weekday $\mathrm{n}=14$ & 13 & $92.86 \%$ \\
& Weekend $\mathrm{n}=14$ & 12 & $85.71 \%$ \\
\hline
\end{tabular}

\section{DISCUSSION}

\section{Turbidity}

Turbidity involves the amount of suspended or colloidal particles that causes light to be scattered and absorbed rather than transmitted. ${ }^{4}$ Suspended materials found within the melted ice samples collected include fish scales, particulates, and splinters of wood. In the study, the mean turbidity value for all samples fell within the PNSDW standard limit of 5 NTU, which is set for aesthetic acceptability. Effective chlorination takes place at turbidity levels of $0.1 \mathrm{NTU}$ and below. ${ }^{3}$ High turbidity levels are associated with high levels of organic carbon which create a chlorine demand that in turn interferes with the maintenance of free residual chlorine. Although turbidity of ice samples is not a definitive test for the quality of ice sold in markets, it is still a useful as an early indicator of the possible presence of pathogens ${ }^{5}$ and other potentially harmful chemicals in the water. This could be associated with the instability of water utilities which may have contributed to the turbidity of pre-manufactured water. Furthermore, the conditions of market and way of handling could also contribute to the increased turbidity of ice samples due to the presence of fish scales and particulates on market floors. Additionally, the consumption of highly turbid water may constitute a health risk as excessive turbidity can protect pathogenic microorganisms from the effect of disinfectants, and also stimulate the growth of bacteria. ${ }^{6}$

\section{Apparent Color}

The maximum limit for apparent color set by the PNSDW is 10 color units (CU). All samples were in accordance with the standard limit set as shown by the range of apparent color results from 0 to $5 \mathrm{CU}$ with a median of 0 and average of
2.32 CU. Color is a water quality indicator more focused on aesthetics and consumer acceptability. Most of organic debris produces yellow-brownish appearance, which will cause reluctance of consumers to drink the water. True and apparent colors are two different appearances of water. The color of original sample prior to filtration or centrifugation treatments is known as the apparent color. Apparent color includes both the substances within the water sample and additional suspended matter. It reflects the color seen by the consumers after the ice has melted provided that they do not subject the water to any filtration or centrifugation treatment, which is highly unlikely. True color, on the other hand, is the color of water after the processes aforementioned have removed turbidity. There exists a relationship between apparent color and turbidity as both parameters are involved with substances and suspended matter present in the water. Mean apparent color of the samples from the three markets was in concordance with those market's mean turbidity values. A study by Edwards et al. demonstrated the relationship between apparent color and turbidity. The study observed that the mechanisms of color removal through the reduction of humic acids are closely associated with the decrease of water's turbidity. ${ }^{7}$

\section{Iron}

Iron is a metallic element known to cause aesthetic issues in drinking water. Globally, it has been identified as a source of water discoloration and metallic taste. All samples included in the study were within the PNSDW iron standard of $1 \mathrm{mg} / \mathrm{L}$ and US EPA and EU standards of 0.3 and $0.2 \mathrm{mg} / \mathrm{L}$, respectively. As of 2011, the World Health Organization does not have established guidelines for iron, but it does acknowledge that aesthetic issues may occur. In a study by Sain and Dietrich, it was found that many consumers are able to detect a discoloration due to ferric (III) iron at the US EPA standard, $0.3 \mathrm{mg} / \mathrm{L}$. This standard is widely used in the international community and may not be sufficient for protecting against discoloration in drinking water under all drinking water conditions of different glass sizes, colors, and water volumes. The same goes for the EU standard, as $84 \%$ of subjects in the study were able to detect a discoloration due to $0.18 \mathrm{mg} / \mathrm{L}$ of iron. ${ }^{2}$ The standards set in the PNSDW are based on recommended guidelines by international institutions such as the US EPA; however, when compared to international standards, the values are not as strict because too stringent standards could limit the 
availability of water supply that meet such levels. National standards are influenced by national priorities and economic factors. ${ }^{9}$ Aside from aesthetic considerations, the presence of iron may be a cause for concern during the chlorination process. Chlorine reacts with oxidizable compounds such as ferrous ion to produce chlorinated organic compounds, which can result to health complications in the long run. ${ }^{4}$

The results of the study showed relationship among the parameters used in the assessment of ice, particularly: $\mathrm{pH}$, residual chlorine and presence or absence of $E$. coli.

\section{$\mathrm{pH}$}

The intensity of acid and alkaline condition of a solution is expressed through $\mathrm{pH}$ values. The acceptable $\mathrm{pH}$ values within the range of 6.5 to 8.5 are based on aesthetic consideration only. ${ }^{3}$ In water quality assessment, $\mathrm{pH}$ is an important operational water quality parameter. It is an important factor in chemical coagulation, disinfection, water softening, and corrosion control. The $\mathrm{pH}$ levels may aid in the detection of microorganisms within water samples, as they were shown to be linked with the efficiency of chlorine disinfection. Keeping the $\mathrm{pH}$ value within the recommended range is important to ensure the effectiveness of disinfection. ${ }^{10}$ Bacterial and viral inactivation is dependent on the concentration of hypochlorous acid $(\mathrm{HOCl})$ which is predominantly present at $\mathrm{pH}$ values between 4 and 7 . On the other hand, the hypochlorite ion $\left(\mathrm{OCl}^{-4}\right)$ which is predominantly present at $\mathrm{pH}$ values greater than 8 is not an efficient bactericide nor virucide. Maintaining the $\mathrm{pH}$ at the standard range is also necessary for an optimal degree of disinfection without the risk of adverse health effects as well as corrosion. The average $\mathrm{pH}$ of ice samples from all markets is 6.16 with a range of 5.17 to 7.53 and median of 6.11 . The majority of the ice samples (67.86\%), however, fell below the lower limit of standard range and showed more acidic values. The recorded $\mathrm{pH}$ values of ice samples can be associated with the presence of microorganisms and coliforms due to insufficient activity of residual chlorine for disinfection. One study performed in Ethiopia compared $\mathrm{pH}$ levels of tap water and household water. Tabulated results of $\mathrm{pH}$ values in household and tap water showed that household water has higher $\mathrm{pH}$ values. In relation to the $\mathrm{pH}$ values, household water was also observed to have higher number of total coliforms. ${ }^{6}$

\section{Residual Chlorine}

The accuracy of the residual chlorine test varies with the $\mathrm{pH}$ level of a sample. The test for residual chlorine uses the colorimetric determination method with color card and sliding comparator. In this method, a weakly acidic solution enables the reaction of free chlorine with diethyl-pphenylenediamine (DPD) to form a red-violet dye. To ensure the accuracy of color formation upon detection of chlorine in the ice samples, aliquots were maintained in a weakly acidic condition with $\mathrm{pH}$ range of 4 to $8 .{ }^{10}$
The PNSDW standard limit set for residual chlorine is $0.30 \mathrm{mg} / \mathrm{L}$ being the lower limit and $1.50 \mathrm{mg} / \mathrm{L}$ as the upper limit. The standard reflects the ideal free chlorine available for residual disinfection after the water has left the water distribution system. In the case of ice samples sold in three markets, none of the samples complied with the minimum limit set having an average and median of $0.05 \mathrm{mg} / \mathrm{L}$ and a range of $0.05 \mathrm{mg} / \mathrm{L}$ to $0.10 \mathrm{mg} / \mathrm{L}$. During chlorination within a water treatment facility, one may expect that a considerable fraction of bacteria in the water are killed or damaged, while some residual chlorine remain in the water until it reaches the tap. ${ }^{11}$ Presence of residual chlorine in drinking water indicates that: a) sufficient amount of chlorine was added initially to the water to inactivate the bacteria and some viruses that cause diarrheal disease, and b) the water is protected from recontamination during storage. ${ }^{12} \mathrm{~A}$ study by Lim, Delehomme and Capece reported that freezing does not significantly decrease the level of chlorine and that concentrations may persist for as long as one month. Other studies used by the authors further proved that residual chlorine level below $0.07 \mathrm{mg} / \mathrm{L}$ does not maintain the biological stability of water and allows bacterial growth. ${ }^{13}$ From this study, it can be inferred that if ice had undergone adequate chlorine disinfection while still in its liquid state, upon recontamination at any point during transport, storage or handling, it may be able to kill bacteria as residual chlorine levels do not drop significantly upon freezing. As freezing temperatures render the metabolic properties of bacteria inactive, if residual chlorine levels are not enough to kill off bacteria, this may pose a risk to consumers who will use the ice to cool their beverage. As the ice melts, the bacteria present will regain their metabolic activities and may cause harm to the consumers.

\section{Microbiological analysis}

The presence of free residual chlorine in drinking water is correlated with the absence of disease-causing organisms, and thus is a measure of the potability of water. ${ }^{12}$ Coliforms, in the presence of standard residual chlorine levels, are damaged or killed. However, in water samples with less than $0.30 \mathrm{mg} / \mathrm{L}$ of residual chlorine, coliforms may persist, as no residual disinfection would occur. The presence of fecal coliforms and Escherichia coli is a strong indication of recent fecal contamination. ${ }^{14}$ If one is to use a presence/absence test to test for microbiological quality, the PNSDW states that E. coli should be absent in the sample as it is the designated indicator organism of the PNSDW for fecal contamination. ${ }^{3}$ Twenty-five out of the 28 samples were confirmed to be positive for $E$. coli by the indole test. Having 25 positive samples mean that the ice samples are not compliant with the standards set by the PNSDW. Although ice manufacturers are required to use potable drinking water, the fate of ice post-production is unregulated. Given that no legislation is explicitly directed to ice manufacturers and vendors postproduction, contamination of ice may occur. All samples 
from Market A were positive for E. coli, compared to Market $\mathrm{B}$, which has $83.33 \%$ positive samples, and Market $\mathrm{C}$ with $87.5 \%$ positive samples. Contaminated ice is a possible vehicle in the oral-fecal route of infection. ${ }^{15}$ Usually, the presence of $E$. coli coliforms and a variety of microorganisms in ice are indicators of poor water quality, and lack of hygiene in the production or handling of ice or both. ${ }^{16}$

In the Philippines, ice blocks in wet markets are transferred from the delivery vehicle to the market stalls by dragging the ice on the ground. Generally, Market A had more samples that are not compliant with the standards compared to samples from Markets B and C. Market A ice samples had more suspended materials which may have been caused by the market's environment and handling of ice by the vendors. While some of the ice vendors in Markets B and $\mathrm{C}$ store their ice in freezers and in enclosed stalls, vendors in Market A either leave their ice in the open or they make use of old tarpaulin posters, cloth, and plastics to cover the ice. Unsanitary transport, handling and storage, and contact with particles and sediment from the ice samples' proximal environment are just some of the reasons that may cause the contamination of ice. Since the stocks of ice blocks are periodically renewed and large ice blocks are not stored for extended periods of time due to insufficient and in some cases a total lack of freezing apparatus, any form of foreign substances found in a sample indicates recent contamination. Although these causes pertain to practices post-production of ice, contamination may occur during production. In a study by Gerokomou et al, ice contamination can be attributed to contaminated initial water source or storage tanks and equipment, specifically due to seeding from the main supply, faulty plumbing which allows backflow from the drains and irregular cleaning of machines. ${ }^{1}$ Also, most of the vendors from all three markets handle their products with bare hands which may also cause contamination. The quality of ice at the point of distribution was assessed in the study but it should be noted that ice could be contaminated during production, handling, storage and transport. Nevertheless, the findings of the study warrant strict regulation of ice production and monitoring of ice post-production from delivery to storage up to distribution. Ice quality should also be regulated alongside water quality.

\section{CONCLUSION}

The results of the study show that the quality of ice sold in the selected wet markets in the city of Manila do not meet standards. These findings support the need for guidelines and the need for proper regulation of handling and storage of ice blocks sold in wet markets from the point of manufacturing until the point of distribution. Overall, the study showed that the contamination of ice blocks in public markets with fecal coliforms is a reality that threatens the consumers and the general public with the risk of the development of disease and infection. With the data obtained, further studies must be done to establish where contamination takes place, monitoring of the entire process of ice production from the level of the manufacturer to ice vendors in wet markets is also recommended. It is also suggested to compute for the sample size based on statistical analysis to increase the statistical power for the generalizability of the results. For markets, data supports the need for the market administrators to monitor and improve the general sanitation and condition of the markets, specifically ice stalls. They are also advised to ensure implementation and compliance of ice vendors to subsequent laws to be formed regarding ice handling and storage.

\section{Acknowledgment}

The authors gratefully acknowledge the staff of the Department of Environmental and Occupational Health and the Department of Medical Microbiology of the College of Public Health: Mr. Adrian Paul M. Agravante, Mr. Jhon Rey Bayatan, Ms. Mary Anne C. Sison, and Ms. Abigail Tan.

\section{Statement of Authorship}

All authors have approved the final version submitted.

\section{Author Disclosure}

All authors have declared no conflict of interest.

\section{Funding Source}

The project was partially funded by the Department of Environmental and Occupational Health, College of Public Health, University of the Philippines Manila.

\section{REFERENCES}

1. Gerokomou V, Voidarou C, Vatopoulos A, et al. Physical, chemical and microbiological quality of ice used to cool drinks and foods in Greece and its public health implications. Anaerobe [Online]. 2011 Dec 31 [cited 2016 Spet 24];17(6):351-3. Available from: http://www. sciencedirect.com/science/article/pii/S1075996411001132.

2. Code on Sanitation of the Philippines $1975(\mathrm{PH})$. Available from: http://www.doh.gov.ph/sites/default/files/publications/Chapter_3_ Food_Establishments.pdf.

3. Department of Health. Philippine National Standard for Drinking Water 2007 [Online]. Sta. Cruz, Manila: Department of Health; 2007 [cited 2016 Oct 1]. 35 p. Administrative Order No.: 20070012. Available from: http://www.lwua.gov.ph/downloads_14/ Philippine\%20National\%20Standards\%20for\%20Drinking\%20 Water\%202007.pdf.

4. American Public Health Association, American Water Works Association \& Water Environment Federation. Standard Methods for the Examination of Water and Wastewater. 22nd Edition. Washington: American Public Health Association; 2012. 2-5 to 2-7, 2-12 to 214, 2-69, 3-77 to 3-80,4-69, 9-65, 9-93 to 9-94.

5. Schwartz J, Levin R, Goldstein R. Drinking water turbidity and gastrointestinal illness in the elderly of Philadelphia. Journal of Epidemiology \& Community Health. 2000;54(1):45-51.

6. Yasin M, Ketema T, Bacha K. Physico-Chemical and bacteriological quality of drinking water of different sources, Jimma zone, Southwest Ethiopia [Online]. 2015 Oct 5 [cited 2016 Sept 24];8: 541. Available from: https://www.ncbi.nlm.nih.gov/pmc/articles/PMC4594903/ DOI: $10.1186 / \mathrm{s} 13104-015-1376-5$. 
7. American Water Works Association. Removing Color Caused by Humic Acids. [Online]. 1985 March [cited 2017 March 16] Available from: https://www.awwa.org/publications/journal-awwa/abstract/ articleid/11299.aspx.

8. Sain, A., Dietrich, A. Rethinking aesthetic guidelines for manganese and iron in drinking water [Online]. 2015 Nov 11. [cited 2017 Mar 6];64(7):775-82. Available from: http://aqua.iwaponline.com/ content/64/7/775.

9. Vital, P. G., Dimasuay, K. G., Widmer, K. W., \& Rivera, W. L. (2014, May 14). Microbiological Quality of Fresh Produce from Open Air Markets and Supermarkets in the Philippines. The Scientific World Journal, 2014, 1-7. DOI:10.1155/2014/219534.

10. MERCK KGaA. Chlorine and $\mathrm{pH}$ Test for the determination of free chlorine and $\mathrm{pH}$.[Online].Darmstadt,Germany:MERCK KGaA;2011 [cited 2016 Oct 1]. 1 p. Available from: http://www.merckmillipore. com/INTERSHOP/web/WFS/Merck-INTL-Site/en_US/-/USD/ ShowDocument-File;pgid=8iFMKfaYPCFSRpEowZVgbI720000_ Aefqz16;sid=5nO_y6WuTBDBy_2imvuvQ0v7X_V91LCynpPzt x0O18EGLS3APrH1r1TCo00j6x-jXZ-R0nbYJU5GY_pploNX_ d2ChNI7whE1smMz-AM4ZnPb3a_VParbem-yXSLXzRsGoP cGTWfxbh1nCWaTH9uR0nbY?ProductSKU=MDA_CHEM$117924 \&$ DocumentId=14470.ProNet\&Document Type=PI\&Langua ge $=\mathrm{EN} \&$ Country $=\mathrm{NF} \&$ Origin $=\mathrm{PDP}$.

11. Ikonen J, Pitkänen T, Miettinen IT. Suitability of Optical, Physical and Chemical Measurements for Detection of Changes in Bacterial Drinking Water Quality [Online]. 2013 Oct 25 [cited 2016 Sept 25]; 10(11): 5349-63. Available from: http://www.ncbi.nlm.nih.gov/pmc/ articles/PMC3863849/ DOI: 10.3390/ijerph10115349.
12. CDC. Chlorine Residual Testing. [Online]. 2014. [cited 2017 March 10]; Available from: https://www.cdc.gov/safewater/publications_ pages/chlorineresidual.pdf.

13. Lim M, Delehomme C, Capece J. Removal of Residual Chlorine from Drinking-Water by Solar Radiation (UV) and Activated Carbon Filtration. [Online]. 2008 Apr. [cited 2017 Mar 11]; Available from: http://hendryutilities.com/plus/docs/Chlorine_Removal_Report_ Final_080817.pdf.

14. World Health Organization. WHO Drinking Water Quality Guidelines, Standards and Health: Assessment of Risk and Risk Management for Water-related Infectious Disease [Online]. 1st ed. Padstow, Cornwall, UK: TJ International (ltd); 2001 [cited 2016 September 26]. Available from: http://www.who.int/water_sanitation_ health/dwq/iwaforeword.pdf.

15. Fecal Coliform as Indicator Organism [Online]. 1st ed. 29 Hazen Drive, Concord, New Hampshire 03301; 2003 [cited 2016 September 26]. Available from: http://des.nh.gov/organization/commissioner/ pip/factsheets/wwt/documents/web-18.pdf.

16. Chavasit V, Sirilaksanamanon K, Phithaksantayothin P, Norapoompipat Y, Parinyasiri T. Measures for controlling safety of crushed ice and tube ice in developing country. [Online]. 2011 [cited 2017 March 3] Available from: https://www.researchgate.net/publication/223271950_ Measures_for_controlling_safety_of_crushed_ice_and_tube_ice_in_ developing_country. 